\title{
Resenha
}

\author{
Da fantasia de infancia ao infantil na fantasia: \\ a direção do tratamento na Psicanálise com crianças \\ Ana Laura Prates Pacheco
}

São Paulo: Annablume, 2012, 308 p.

\section{DA FANTASIA DE INFÂNCIA AO INFANTIL NA FANTASIA}

\author{
Leomara de Araújo Bürgel
}

\begin{abstract}
()
título do livro de Ana Laura Prates Pacheco nos convoca de imediato a um exercício fonético/semântico, aos moldes do trava-língua, jogo típico da infância que desafia nossas habilidades articulatórias e de interpretação.

O encontro contingente com a infância, a partir de um caso clínico, impôs à autora questões relativas à direção do tratamento psicanalítico com crianças. O trabalho com um menino de 8 anos, interrompido de maneira abrupta e desajeitada, segundo a autora, pôde ser retomado seis anos mais tarde, em função de um traço transferencial que restou, ressaltando uma temporalidade própria da Psicanálise. Esse momento de reinício de análise com Zeti, permitiu, num "só depois" a atualização das indagações suspensas por ocasião da ruptura ocorrida anteriormente, bem como a construção do caso na forma apresentada agora, nesse livro de 308 páginas. Capítulo a capítulo, vão sendo desdobradas questões cruciais para a compreensão da problemática que a clínica com crianças abrange, incluindo seus matizes. Esses temas são fundamentais para que a direção do tratamento ocorra dentro do campo psicanalítico. As páginas que lemos, eu diria quase num fôlego só devido à fluidez com que se apresentam os temas e suas articulações, culminam em um
\end{abstract}

- Psicanalista. Membro da Associação Psicanalítica de Curitiba (APC), Curitiba, PR, Brasil.

Estilos clin., São Paulo, v. 18, n. 3, set./dez. 2013, 630-639. 


\section{Resenha}

final que responde às interrogações e questões propostas pela autora no início do livro sobre a legitimidade, a especificidade e a unidade da clínica psicanalítica com crianças.

O fio ininterrupto que nos conduz pelos cinco capítulos que compõe o livro inicia-se com os belos prefácios de Antônio Quinet, na edição brasileira, e de Pablo Peusner, na edição argentina. Eles anunciam o valor do conteúdo que virá a seguir. Nas palavras do primeiro: "uma questão preliminar a todo tratamento possível de crianças pelo discurso psicanalítico. Eis o subtítulo implícito que apreendo deste livro de Ana Laura Prates Pacheco, parafraseando o célebre artigo de Lacan sobre a psicose" (p. 15). E com o segundo, temos:

O livro que o leitor tem em mãos é dirigido aos psicanalistas que decidiram não recuar frente às crianças. Sua autora, Ana Laura Pacheco, habita o que Lacan chamava "a fronteira móvel da conquista psicanalítica”. E como essa fronteira é móvel, o é tanto para fazer conseguir entrar na Psicanálise o que antes ficava de fora, como para que os psicanalistas que retrocederam revisem sua posição e entrem (p. 21).

$\mathrm{O}$ ato analítico visa à criança ou ao sujeito? A partir da hipótese de que os problemas enfrentados na direção do tratamento psicanalítico com crianças são decorrentes da sobreposição do sujeito à criança e também da valorização da infância como fase de vida em detrimento do conceito de infantil como lugar, a autora explicita 
os objetivos de seu trabalho. Primeiramente, evidenciar que a partir da obra de Jacques Lacan pôde-se propor uma clínica com crianças norteada pelos conceitos de sujeito do inconsciente, tempo lógico e estrutura clínica. O conceito de infantil é um operador fundamental da clínica psicanalítica, o qual a distancia radicalmente da posição de tomar a criança como um objeto natural, como o fazem a ciência biológica e a psicologia do desenvolvimento. Em decorrência dos desdobramentos dos argumentos preliminares, surge um segundo objetivo, considerado como o principal do trabalho, que é sustentar a unidade da clínica psicanalítica pela via da articulação lógica do sujeito ao objeto na fantasia fundamental.

A autora do livro mostra com clareza a partir de uma citação do seminário $A$ identificação a proposta ética de Lacan quanto à posição do analista diante do sujeito, independentemente da sua idade:

O que me faz precipitar-me como criança, é o evitamento da verdadeira resposta, que deve começar bem mais cedo que qualquer outro termo da frase. A resposta ao que sou eu? não é nenhuma outra coisa de articulável, da mesma forma em que lhes disse que nenhuma demanda é suportada. Ao que sou eu? não há resposta no nível do Outro que o deixa-te ser. E toda precipitação dada a esta resposta, qualquer que seja ela na ordem da dignidade, criança ou adulto, não passa de eu fujo ao sentido deste deixa-te ser. O que está em questão em toda pergunta formulada não está no nível do que sou eu?, mas no nível do Outro, e sob a forma que a experiência analítica nos permite revelar, do que queres?.... A análise descobriu que aquilo com que o sujeito tem a ver é o objeto da fantasia, na medida em que este se apresenta como o único capaz de fixar um ponto privilegiado naquilo a que é preciso chamar, como princípio do prazer, uma economia regulada pelo nível do gozo (p. 276).

Também acrescenta que, sendo a definição lacaniana de criança correlata à realização do objeto a na fantasia, pode-se propor que todo sujeito neurótico tomado em análise se posiciona num lugar infantil. Sendo assim, o ato analítico sempre visa o infantil.

No primeiro capítulo somos relembrados de que a ideia contemporânea da criança como um ser em desenvolvimento diz respeito a uma construção criada ao longo das transformações sócio-históricas e econômicas a partir da Idade Média. Tal construção é chamada pela autora de "construção de uma fantasia de infância". Apoiando-se no trabalho do historiador francês Philippe Ariès, sobre a história social da criança e da família, entre outros, a autora objetiva compreender como se chegou à concepção moderna de infância no mundo ocidental. Para responder à questão sobre se a Psicanálise teria ou não

632 Estilos clin., São Paulo, v. 18, n. 3, set./dez. 2013, 630-639. 
uma nova visão sobre a criança, interroga o conceito de criança até seus dias atuais e discorre sobre os dispositivos sociais, econômicos e políticos criados em torno da infância, gerando ressonâncias nas especialidades e modalidades de cuidar da criança. Nessa viagem pela história podemos acompanhar desde a não especificidade da criança na idade medieval até uma especificidade radical no século XXI, quando Freud então acorda a criança do sono da razão e do desejo ao substituir a compreensão da sexualidade infantil, a partir de uma visão desenvolvimentista ou educativa, por outra que enfatiza a fantasia. Aponta para os encaminhamentos da noção de infância nos dias de hoje e alerta sobre as dificuldades que a clínica psicanalítica com crianças tem enfrentado ao longo da história. Estas ligadas à possibilidade de se anular o conceito de "infantil" sobrepondo a ele a ideia de infância como fase de vida. Dessa forma, corre-se o risco de essa clínica ser reduzida a uma "pedagogização do sexo".

No capítulo seguinte, Laura Pacheco faz uma rica apresentação das "direções" seguidas pelos psicanalistas que se dispuseram a atender crianças, a partir de Freud. Nesse panorama encontramos a controvérsia entre Ana Freud e Melanie Klein sobre Pedagogia ou Psicanálise, as contribuições de Winnicott sobre o brincar, a realidade e a fantasia e também as questões sobre a criança na estrutura familiar a partir das experiências de Françoise Dolto e Maud Mannoni. A "nota sobre a criança" de Jacques Lacan e a defesa pela unidade da Psicanálise defendida por Rosine e Robert Lefort também são discutidas pela autora. Em uma citação de Manonni, do livro $A$ criança, sua doença e os outros, podemos vislumbrar o nível e o cunho das questões abordadas:

Deparamos com esse problema cada vez que nos ocupamos com crianças: a análise é então confrontada à sua própria representação da infância, e o peso de suas manifestações inconscientes se refletirá na orientação dada à cura; a criança e sua família interpelam o analista no que há de mais antigo, como temores, defesas e angústia - é sem cessar levado a um plano em que se opera a confrontação de cada um ao problema do desejo, da morte e da lei (p. 93).

É inevitável recorrer às noções de política, tática e estratégia, propostas por Lacan, como planos diversos na direção do tratamento, para um posicionamento diante das situações com as quais o analista é confrontado na direção da cura. A autora, percorrendo a história das experiências dos psicanalistas que se propuseram a trabalhar e teorizar com a clínica com crianças, esclarece como se deu a divisão 
da Psicanálise em psicanálise de adultos e psicanálise com crianças.

Traz como um debate atual no campo lacaniano a questão sobre o tempo da fantasia e o fim de análise. Com palavras de Laurent (1999), acrescenta: "Na criança, como no caso do adulto, se trata de que o sujeito tenha construído suficientemente a fantasia que o anima, com a versão de objeto de que disponha segundo a idade que tenha".

Desenvolve tal tema apoiando-se em textos de autores como Soler, Sauret e Miller, entre outros. O trabalho com crianças impõe aos psicanalistas questões sobre a relação do sujeito com o corpo, com o desenvolvimento, com os pais, com tempo, etc. Segundo a autora, tais questões nos remetem à relação do sujeito com a realidade. No campo da Psicanálise, isso, por sua vez, exige uma reflexão sobre o conceito de fantasia e seus desdobramentos quanto às "relações de objeto". O ensino de Lacan, a partir de sua concepção de sujeito do inconsciente e do diagnóstico estrutural, permitiu uma posição em defesa da unidade da clínica psicanalítica.

Conclui o capítulo, novamente com as palavras de Laurent (1999): "Lacan deixa aberta uma questão: existe algo que separa a criança da pessoa grande; certamente não é a idade, nem o desenvolvimento, tampouco a puberdade. No fundo, o que separa a criança da pessoa grande é a ética que cada um faz de seu gozo.
A grande persone é aquela que se faz responsável de seu gozo.” (p. 41).

$\mathrm{Na}$ parte seguinte, intitulada: "A bolsa ou a vida? A escolha forçada e o sujeito", a autora retoma em detalhes a questão relativa à constituição do sujeito em psicanálise, ao longo do ensino de Lacan. Como se conquista a entrada no mundo dos homens? Nesse momento a linguagem ganha todo seu realce, uma vez que é fundante da dimensão humana. Como nos diz a autora, não se trata de um determinismo linguístico. A teoria lacaniana do sujeito exige uma formalização sobre o ato, incluindo aí uma nova forma de pensar a temporalidade. Para esclarecer o cunho de tal afirmação, a mesma percorre o trabalho de Lacan sobre a constituição do sujeito, pontuando e mostrando de forma clara as formalizações conceituais que foram sendo elaboradas por ele no decorrer dos seus seminários, a partir de exigências lógicas que se impunham até a construção do objeto $a$. Um resgate das funções da linguagem é realizado, incluindo as contribuições de Saussure e Lévi-Strauss, da obra de Freud, e sobretudo da leitura desta, feita por Lacan. No seu ensino, o narcisismo de Freud é retomado via Esquema Óptico mostrando a formação do eu (je) - da insuficiência à antecipação; o Esquema L ilustra os problemas levantados pelo eu e pelo outro e pela língua e a fala, na relação com o semelhante atravessado pelo $\mathrm{Ou}$ -

634 Estilos clin., São Paulo, v. 18, n. 3, set./dez. 2013, 630-639. 
tro, que é o lugar do simbólico. Segue discorrendo sobre a constituição do sujeito em Lacan, a partir da interrogação de como o sujeito evanescente poderia unir seu desejo à lei que o constitui. Para isso Lacan articula a teoria sobre a constituição do sujeito com o Complexo de Édipo, em Freud. A mola de relação do sujeito com o mundo é a falta de objeto e é sobre esse fundo de ausência que o falo se apresenta como objeto privilegiado do desejo humano. A partir da tríade imaginária: mãe, criança e falo, Lacan propõe três categorias de falta de objeto: frustração, castração e privação, a partir das quais explica os passos, na verdade, tempos lógicos para a entrada no simbólico. O terceiro tempo, o da castração, consiste na ascensão do falo materno como simbólico. Sendo assim, a função paterna é uma experiência metafórica que possibilita a transposição do Édipo. Na sequência das formalizações teóricas, a metáfora do Nome-do-Pai explica como o pai torna-se portador da lei.

Com a construção do Grafo do Desejo, as duas determinações que compõem a teoria do sujeito em psicanálise são formalizadas a um só tempo. Por um lado a determinação objetiva que se refere à lei da linguagem e por outro a determinação subjetiva que remete à posição do sujeito e sua estratégia particular do desejo. A simultaneidade entre o eixo diacrônico relativo ao deslize da cadeia e o eixo sincrônico que se refere ao corte estarão sempre presentes no Grafo. O cruzamento entre esses dois pontos define o ponto pelo qual o sujeito para o deslizamento da significação. Isso nos remete a uma formulação topológica que torna indissociáveis as categorias de espaço e tempo. $\mathrm{Na}$ sequência lógica, Lacan propõe como elementos mínimos da estrutura uma bateria de dois significantes (o traço unário é a gênese da diferença que constitui o sujeito e dá sustentação a toda cadeia de significantes) e conduz o trabalho para a extração do objeto, demonstrada a partir da topologia da fantasia. Esta é definida como a fórmula da organização subjetiva, pois é a partir da ligação paradoxal entre o sujeito e objeto, em função do corte estrutural, que se pode constituir a realidade. A função do objeto a na dinâmica psíquica é a de estruturar o processo progressivo-regressivo que constitui a relação do sujeito com sua realidade psíquica. Essa função de objeto exige uma inovação topológica estrutural, que mostre interior e exterior.

No penúltimo capítulo, Ana Laura Pacheco desdobra a questão da temporalidade na clínica com crianças a partir de três tópicos: o diagnóstico estrutural, a exploração da estrutura e a noção de ato em psicanálise. A "função diagnóstica" que orienta o psicanalista ao longo da direção do tratamento se impõe a partir da premissa de que se realiza com crianças a verdadeira psicanálise. O diagnóstico em psicanálise é deslocado do sintoma para a lógica da fantasia, que é o que 
permite ao sujeito realizar sua trajetória na estrutura. Esta, por sua vez, é definida pelo modo como o sujeito se posiciona em relação à estrutura universal da linguagem definindo-se precocemente.

Mas qual é o estatuto da passagem do tempo no humano? A problemática do que é transitivo e do que não se transforma é crucial para se pensar o conceito de cura em psicanálise. A lógica da fantasia é o operador conceitual que permitirá articular o nível de fixação e de ficção com a variabilidade do destino.

E como fica a questão da decisão e das "escolhas" do sujeito? No terceiro tópico a autora esclarece que a constituição do sujeito proposta por Lacan exige a noção de ato. O imaginário de uma continuidade temporal entre o adulto e a criança, proposto na cultura, pode ser questionado pela Psicanálise a partir da sua concepção de sujeito. Lacan propõe uma leitura estrutural do Complexo de Édipo contra uma abordagem desenvolvimentista da escola inglesa, trazendo a ideia de retroação. Na Psicanálise o tempo caminha do futuro para o passado. Voltando a questão da decisão do sujeito, temos Soler (1997, p. 62) que nos alerta: "A alienação é o destino. Nenhum sujeito falante pode evitar a alienação. É um destino ligado à fala.... A separação requer que o sujeito 'queira' se separar da cadeia significante".

No quinto e último capítulo do livro, a autora aprofunda a reflexão sobre o lugar do infantil na construção da fantasia. Afirma que as questões em torno da fantasia oferecem a arena onde ocorrem os principais embates quanto ao atendimento psicanalítico com crianças. Com a diferenciação que Lacan faz entre memória e rememoração, temos que a clínica psicanalítica é aquela que permite ao sujeito construir sua fantasia fundamental a partir da rememoração, da reestruturação e da ressubjetivação, possibilitadas pelo deslocamento significante. $\mathrm{Na}$ relação do sujeito com a realidade, temos que a mesma sendo correlata da fantasia é sustentada pelo Nomedo-Pai, ordenador das relações de objeto no ser humano. Seguindo as exigências lógicas, Lacan retoma a questão da pulsão. A dialética do desejo, embora ordenada pelo falo enquanto significante, é, ao mesmo tempo, regulada pela fantasia enquanto montagem pulsional. Nessa direção, levando em conta o aspecto da fantasia não alcançado pela linguagem, ela é formalizada como escrita. Desloca-se o debate do plano da realidade para o plano da verdade. A articulação entre o plano da verdade e o significante será proporcionada pela lógica da fantasia. Esta, sendo a escrita da impossibilidade da relação sexual e da relação de objeto, aponta, portanto, para a falta estrutural do

636 Estilos clin., São Paulo, v. 18, n. 3, set./dez. 2013, 630-639. 
significante para nomear o ser. Enquanto montagem a fantasia é construída em análise, pois a entrada em análise supõe a passagem da linguagem comum a uma linguagem artificial que, sob transferência, marca a singularidade da construção fantasmática.

No momento de concluir, a questão da direção do tratamento psicanalítico é retomada. Relembrando uma frase de Lacan de que a clínica psicanalítica é aquela que opera "sobre a fantasia" a autora afirma que "operar sobre a fantasia" é a política do tratamento sustentada pelo desejo do psicanalista, qualquer que seja a idade cronológica do sujeito. A sobreposição dos três planos discriminados por Lacan na direção do tratamento psicanalítico - política, tática e estratégia - servem segundo ela para compreender várias questões que surgem na clínica com crianças.

Para Lacan:

Os sentimentos do analista só têm um lugar possível nesse jogo: o do morto; e que, ao ressuscitá-lo, o jogo prossegue, sem que se saiba quem o conduz. Eis por que o analista é menos livre em sua estratégia do que em sua tática. Vamos adiante. O analista é ainda menos livre naquilo que domina a estratégia e a tática, ou seja, em sua política, onde ele faria melhor situando-se em sua falta-a-ser, do que em seu ser. (Lacan, 1998, pp. 593-594)

É importante considerar que é o plano político que possibilita diferenciar o analista do mestre, cuja posição pode ser inesperadamente ocupada na clínica com crianças, uma vez que esta tem a tendência de "ressuscitar" os sentimentos do analista embaraçado com sua própria fantasia de infância.

Com as reflexões realizadas foi possível, segundo a autora, analisar os impasses e as resistências na condução do tratamento de Zeti, apresentado na introdução do livro. Nesse aspecto, três pontos no trabalho foram destacados: a sobreposição da criança ao sujeito, a posição da analista sustentada no Pai e a bola como objeto a (a referência aqui é em relação a um jogo com bola realizado na sessão e que teve um papel importante no desfecho do caso naquela ocasião). Ponto a ponto, a autora articula o caso clínico em questão com os conceitos psicanalíticos, nos oferecendo uma experiência com a escrita do caso, uma ferramenta tão importante na transmissão da Psicanálise.

Quanto à pergunta sobre a especificidade na clínica com crianças, feita desde o início, a autora responde que é a um só tempo sim e não. Desenvolve tal afirmativa, lembrando que trabalhar com os aparentes paradoxos que a clínica com crianças apresenta requer 
utilizar a lógica do "não todo": "não existe criança para a qual não haja especificidade". $\mathrm{Na}$ medida em que "a criança" é um efeito de discurso, propõe que o trabalho com crianças deva ser realizado com uma ferramenta construída por Lacan em $O$ seminário, livro 17: o avesso da psicanálise, 1960-1970.

Certamente o leitor, sobretudo aquele que se aventura na clínica com esse sujeito chamado criança, encontrará no livro de Laura Prates Pacheco uma leitura empolgante. Uma clínica que, diga-se de passagem, causa polêmica entre psicanalistas no tocante a sua especificidade e a sua legitimidade. E que por isso mesmo exige que certas interrogações sejam respondidas pelo analista que se dispõe a trabalhar aí.

Trabalhar com crianças nos mostra de maneira muito clara a dimensão viva do ato analítico, o qual se dirige ao sujeito convocando-o a se servir da língua de uma maneira singular que possibilita por sua vez uma resposta singular. Convoca-o a partir de uma temporalidade lógica, a construir para si um lugar no tempo e no espaço, que possibilite o laço com o Outro. Permite-nos também observar a dependência desse sujeito, em plena experiência de construção de um lugar subjetivo-discursivo, da rede significante dos pais que diz respeito justamente ao seu lugar na fantasia deles. As táticas e estratégias das mais diversas, consonantes com cada caso e com o estilo do analista,

638 Estilos clin., São Paulo, v. 18, n. 3, set./dez. 2013, 630-639. 
não devem, no entanto, nos afastar da política que diz sobre os fins do tratamento. A ética concernente à Psicanálise diz respeito ao sujeito do inconsciente, independentemente do tempo em que ele se encontra: da infância, da adolescência ou aquele do adulto.

Finalizo com uma frase de Lacan, do texto "A carta roubada", e que a autora cita nos "Agradecimentos": "porque uma carta sempre chega ao seu destino" (p. 8).

\section{REFERÊNCIAS}

Lacan, J. (1998). A direção do tratamento e os princípios de seu poder. In J. Lacan, Escritos. (V.Ribeiro, trad., pp. 591-652). Rio de Janeiro: Jorge Zahar.

Laurent, E. (1999). Hay un fin de análisis para los niños. Buenos Aires: Coleccion Diva.

Soler, C. (1997). O sujeito e o Outro II. In R. Feldstein, B. Fink, \& M. Jaanus (Orgs.), Para ler o seminário 11 de Lacan (D. D. Estrada, trad., pp. 58-67). Rio de Janeiro: Jorge Zahar.

laburgel@gmail.com Rua Francisco Rocha, 420/162 -

Bloco I 80420-130 - Curitiba - PR - Brasil.

Recebido em julbo/ 2013. Aceito em setembro/ 2013. 